\title{
correspondence
}

\section{Driving and substance misuse}

Sir: We read with interest the article by Bradbeer et al in the July 2001 edition of the Psychiatric Bulletin (25, 252-254). We have recently completed a cross-sectional survey of the recording in case notes of specific advice given to patients. They were attending a substance misuse facility (Leeds Addiction Unit). The advice we were interested in was that given by addiction therapists, reminding patients of their duty as drivers to inform the Driver and Vehicle Licensing Agency (DVLA) and their insurers that they have a prescribed disability (i.e. alcohol and drug misuse, whether or not amounting to dependence (Harris, 2000)).

Seventy-six sets of notes, out of 125 randomly selected cases (5 per current keyworker/therapist) were located. The notes were read in their entirety, including contributions from all sources (i.e. not just medical staff entries) to identify any comment indicative of consideration being given to driving, and particularly to advising/reminding the patients of their need to inform the DVLA and their insurer. The latter is important because altering the risk under which insurance is agreed, by failure to declare a relevant condition, will compromise or even render void the insurance. This could have potentially devastating legal and financial consequences for any particular individual.

Thirteen sets (17\%) of the located notes had any reference to driving being discussed or considered. Of these, four (5\%) mentioned DVLA and four (5\%) mentioned insurance considerations, but only three cases (4\%) mentioned both DVLA and insurer. As a result of this survey, and the discussion it prompted, practice has been changed so that all new patients are reminded at their first assessment of their responsibilities to inform the DVLA and their insurer of the necessary information. Existing patients will be reminded periodically too, with documentation to this effect in the case notes. We do not feel that we need to take further action at present. In the future, however, if we do have reason to believe that a patient is continuing to drive despite clear explanation and efforts to persuade him or her to desist, we will need to hold a multi-disciplinary review to discuss how to proceed. If necessary we would take legal advice before breaching confidentiality by informing the DVLA, as per General Medical Council guidance (GMC, 2000).

We agree with Bradbeer et al that imparting information to patients about DVLA fitness to drive regulations is important. We also agree that "the regularly demonstrated poor retention of information following clinical interviews" may be particularly important if a clinician was ever challenged to demonstrate that he or she had informed the patient but had not documented this formally. In addition, however, we feel that it is important to point out to patients the insurance implications of their substance misuse. We are currently engaged in a larger project examining the documentation of such advice by medical practitioners in a variety of clinical settings, beyond but including substance misuse psychiatry. Our findings should be of broad interest, considering the DVLA and insurance requirements apply to all areas of clinical medicine.

GENERAL MEDICAL COUNCIL (2000) Confidentiality. London: GMC.

HARRIS, M. (2000) Psychiatric conditions with relevance to fitness to drive. Advances in Psychiatric Treatment, 6, 261-269.

Gill Kirk Specialist Registrar, Duncan Raistrick Clinical Director, Leeds Addiction Unit, Peter Trigwell Consultant in Liaison Psychiatry, Leeds General Infirmary

\section{obituaries}

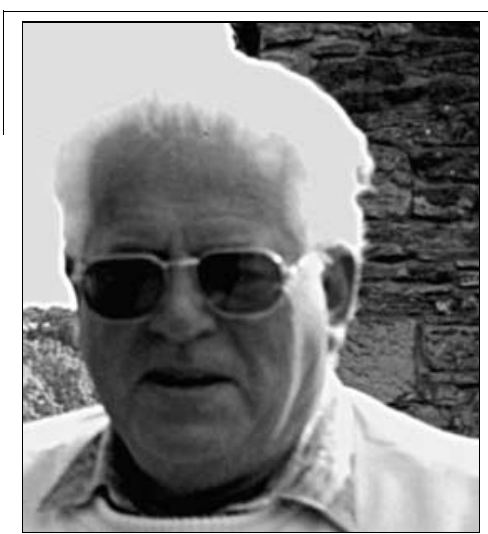

\section{Jerrold Ross Burgess}

Former Consultant Psychiatrist West Cumberland Hospital, Cumbria

Jerrold Burgess died peacefully from heart failure in hospital on 4 January 2001. He was a consultant psychiatrist - his patients would say the consultant psychiatrist - at the West Cumberland Hospital, Whitehaven, and Garlands Hospital, Carlisle, for over 20 years.
He was educated at Dartington and qualified in Dublin in 1956 after completing his National Service in the Army. His subsequent house jobs included a post in paediatrics and he retained a particular interest in the young throughout his career. He trained in psychiatry initially at Bristol, Barrow and Glenside Hospitals, and then moved up to St James' Hospital in Leeds as a senior registrar. When I was seeking a congenial second consultant to share the service for West Cumberland in 1966, he was commended to me by his chief, Julian Roberts, who assured me that I would 